\title{
Definition of the terms "acute" and "traumatic" in rotator cuff injuries: a systematic review and call for standardization in nomenclature
}

\author{
Jonas Pogorzelski ${ }^{1} \cdot$ Bernd Erber $^{1} \cdot$ Alexander ThemessI ${ }^{1} \cdot$ Marco-Christopher Rupp ${ }^{1}$ - Matthias J. Feucht ${ }^{1,2}$.

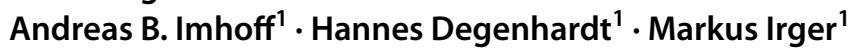

Received: 16 June 2020 / Accepted: 15 October 2020 / Published online: 1 November 2020

(c) The Author(s) 2020

\begin{abstract}
Background Although of high relevance for clinical decision making, there exists no consensus throughout the literature of the terms "acute" and "traumatic" used in the classification of rotator cuff tears. With differing definitions, the comparability of outcome studies may be limited. The aim was to provide a detailed systematic review of the definitions used in the literature and present a suggestion for a standardization in nomenclature based on the findings.

Methods Four different internet databases were searched in February 2020 using the terms ("acute" OR "traumatic" OR "trauma" OR "athlete" OR "young") AND ("rotator cuff tears" OR "rotator cuff tear" OR "rotator cuff" OR "rotator cuff rupture" OR "supraspinatus" OR “infraspinatus" OR "subscapularis" OR "teres minor"). Prospective, retrospective, cohort and case-control studies as well as case series were included. Systematic reviews, cadaveric or laboratory studies and studies on non-traumatic or non-acute rotator cuff tears were excluded.

Results The literature search conducted 10,349 articles of which 10,151 were excluded based on the title, 119 based on the abstract and 33 based on the manuscript. A total of 46 studies were finally included for review and subsequently analyzed. Overall, there exists no consensus neither on the term "acute" nor on "traumatic" in the context of rotator cuff tears in the literature. The time span for acute injuries ranged between 2 weeks and 6 months. For traumatic injuries, only $20 \%$ of the selected studies described a specific and adequate injury mechanism in combination with adequate imaging.

Conclusion The term "acute" should be reserved for RCT showing muscle edema, wavelike appearance of the central part of the torn tendon and joint effusion, which typically requires adequate imaging within 2 weeks from trauma. Repair of acute tears should occur within 8 weeks from trauma to benefit from possibly superior biological healing capacities. The term "traumatic" should be used for a sudden onset of symptoms in a previously asymptomatic patient, triggered by an adequate trauma, e.g., a fall on the retroverted arm with an axial cranioventral force or a traumatic shoulder dislocation.
\end{abstract}

Keywords Rotator cuff tears $\cdot$ Acute $\cdot$ Traumatic $\cdot$ Acute on chronic lesions $\cdot$ Systematic review

\section{Abbreviations}

bFGF Basic fibroblast growth factor

c Comparative study (within the MINORS-Score)

Hannes Degenhardt and Markus Irger contributed equally to this manuscript.

Jonas Pogorzelski

jonas.pogorzelski@tum.de

https://www.sportortho.mri.tum.de

1 Department of Orthopedic Sports Medicine, Hospital Rechts Der Isar, Technical University of Munich, Ismaninger Street 22, 81675 Munich, Germany

2 Department of Orthopaedics and Trauma Surgery, Medical Center, Faculty of Medicine, Albert-Ludwigs-University of Freiburg, Freiburg, Germany
IGF-1 Insulin-like growth factor-1

IL-6 Interleukin 6

IL1- $3 \quad$ Interleukin 1- $\beta$

MRI Magnet resonance imaging

nc Non comparative study (within the

MINORS-Score)

PDGF Platelet-derived growth factor

RCT Rotator cuff tear

ret Randomized controlled trial (within the MINORS-Score)

TGF- $\beta$ Transforming growth factor $\beta$

TNF- $\alpha$ Tumor necrosis factor $\alpha$

VEGF Vascular endothelial growth factor 


\section{Introduction}

Rotator cuff tears (RCTs) are a common shoulder pathology with at least 4.5 million physician visits only in the US every year [1]. Typically, rotator cuff tears occur more frequently in elderly than in younger patients because of an age-related degeneration of the rotator cuff tendons [2]. However, multiple reports observed a rising number of young patients below the age of 45 years suffering from RCT due to a traumatic incident [2-5] or chronic overuse, particularly in overhead athletes [6]. While the treatment of degenerative RCT in the elderly patient is controversial, there is consensus throughout the literature that surgery is generally advised for RCTs in young patients due to possible severe consequences, such as irreparable retraction of tendons, muscular atrophy and poor outcomes with the consequence of a rotator cuff arthropathy [6].

Although younger patients suffering from acute and traumatic RCT tend to have better tendon quality and better biological preconditions for tendon healing, the results published following rotator cuff repair in this population are heterogeneous and comparable to those of elderly patients $[3,7,8]$. A possible explanation might be that etiology is more critical for outcome than age. However, if there exists no uniform definition of the terms "acute" and "traumatic" throughout the literature, comparability of studies may be limited and proof of the aforementioned hypothesis hardly possible.

Therefore, the primary purpose of this study was to conduct a systematic review of the literature and summarize the available definitions of the terms "acute" and "traumatic" with respect to rotator cuff tears. The secondary purpose was to propose criteria for a more specific definition of both terms based on the gained insights. We hypothesized that there exists no consensus for both terms so far.

\section{Methods}

\section{Inclusion and exclusion criteria}

This systematic review was structured according to the PRISMA Checklist [9]. A literature search was performed focusing on studies investigating acute and traumatic rotator cuff tears. Prospective, retrospective, cohort and case-control studies as well as case series written in English and German were included. Systematic reviews, cadaveric or laboratory studies and studies on non-traumatic or non-acute rotator cuff tears were excluded.

\section{Search strategy}

Two reviewers (blinded for review) independently searched electronic databases (PubMed, MEDLINE, COCHRANE Library, and EMBASE) on February 13th, 2020 using the following search term: (acute OR traumatic OR trauma OR athlete OR young) AND (rotator cuff tears OR rotator cuff tear OR rotator cuff OR rotator cuff rupture OR supraspinatus OR infraspinatus OR subscapularis OR teres minor). Furthermore, the references of the included full-text articles were searched for additional studies meeting the inclusion criteria.

\section{Study selection}

Inclusion or exclusion of studies was based on the aforementioned criteria. Two reviewers (blinded for review) independently analysed titles and abstracts of all identified publications and the complete text of eligible articles. Divergences were resolved in collaboration with a third reviewer (blinded for review).

\section{Data extraction and quality assessment}

The following data were abstracted from all included studies: study design, level of evidence, type of imaging used to detect the RCT, time frames used for definition of an acute injury and the definition of the term "traumatic" in the context of an RCT. Level of evidence was assigned according to the widely accepted common grading of Evidence Levels for Primary Research $[10,11]$. The methodological quality of the included studies was assessed using the Methodological Index for NonRandomized Studies (MINORS) [12]. The MINORS checklist consists of 12 items which are scored 0 (not reported), 1 (reported but inadequate) and 2 (reported and adequate) each with a maximum score of 16 for non-comparative studies (nc) and 24 for comparative studies (c). The methodological quality was categorized a priori as follows: a total score of $0-8$ or $0-12$ was considered as poor quality, 9-12 or 13-18 was considered as fair quality and 13-16 or 19-24 was considered as excellent quality, for non-comparative studies and comparative studies, respectively. Since this review aimed to analyze the definitions of the terms "acute" and "traumatic" for RCTs regardless of the patient outcome, MINORS could only evaluate the quality of the study but could not provide information on the quality of the definitions of the aforementioned terms.

\section{Results}

Overall, a total of 10,349 articles matched our search criteria on February 13th, 2020. After implementation of inclusion and exclusion criteria 10,151 were excluded based on the 
title, 119 based on the abstract and 33 based on the manuscript. As shown in Fig. 1, a total of 46 studies could be included with 28 studies defining only the term "traumatic" [3, 5, 13-38] and 18 studies defining both terms, "acute" and "traumatic" [39-56]. No study exclusively defining the term "acute" could be detected. The results of the included studies including MINORS score are presented in Table 1.

For the diagnostic assessment of the rotator cuff, 31 studies within the included publications $(67 \%)$ used magnetic resonance imaging (MRI) $[5,13,15,16,18,20-25,27,28$, $30,31,35-39,42-44,46,48,51-56]$. In an additional six studies (13\%), ultrasound was used for detecting a torn rotator cuff $[14,33,40,45,49,50]$. Three studies (7\%) reported that either MRI or ultrasound was adequate for evaluation of an RCT $[19,34,47]$. Another three studies (7\%) relied on X-rays only [17, 26, 29]. A total of three studies (7\%) did not report use of imaging modalities at all [3, 32, 41].
Of the studies included in this review, histological examinations were only performed in a single study [42]. In this study, two samples of the tendons of each patient were taken and sent to different laboratories for evaluation to distinguish between acute or chronic RCTs based on the absence or presence of hemosiderin. Due to the heterogeneous and contradictory results in this study, the authors later decided to exclude histopathological examinations in their study [42].

\section{Results for defining the term "acute"}

According to the 18 articles defining the term "acute" with regard to RCTs, the time range was defined between less than 2 weeks up to 6 months (Table 1) [39-56]. These studies can be further subdivided into ten studies, using a period of a minimum of two up to a maximum of 6 weeks as time span for an acute RCT [41, 43, 45-49, 51-53] and eight

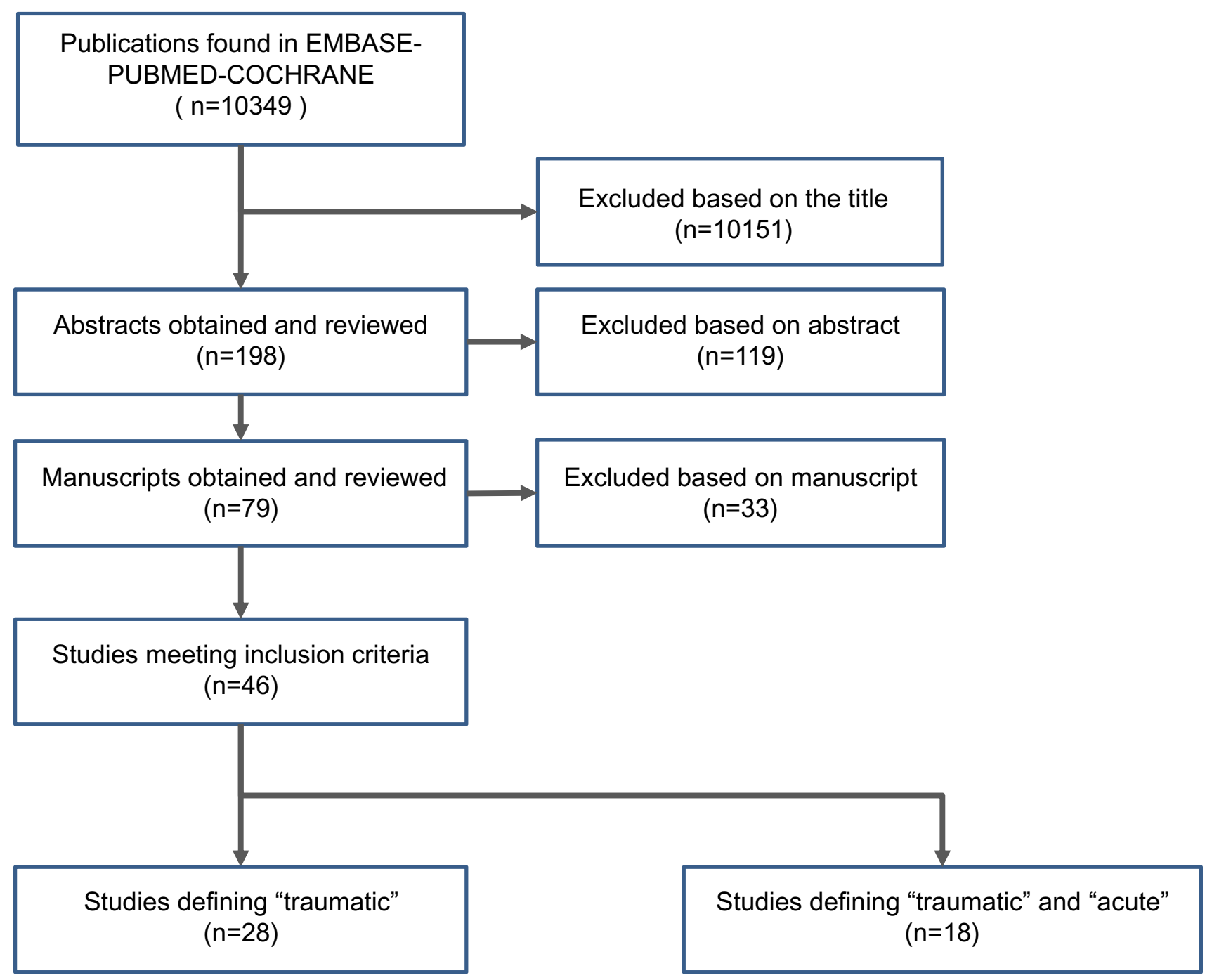

Fig. 1 Flowchart of the study selection process 


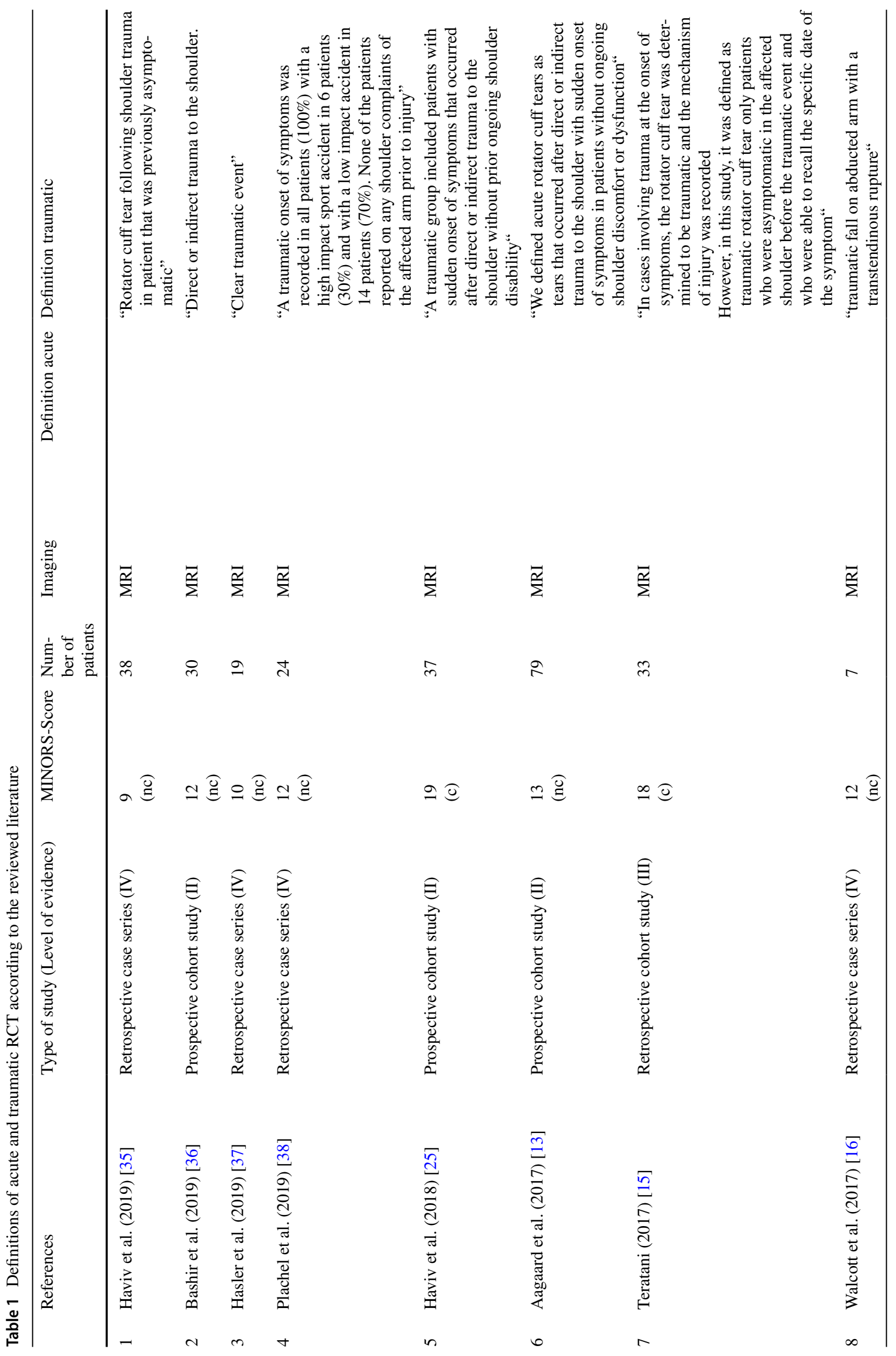




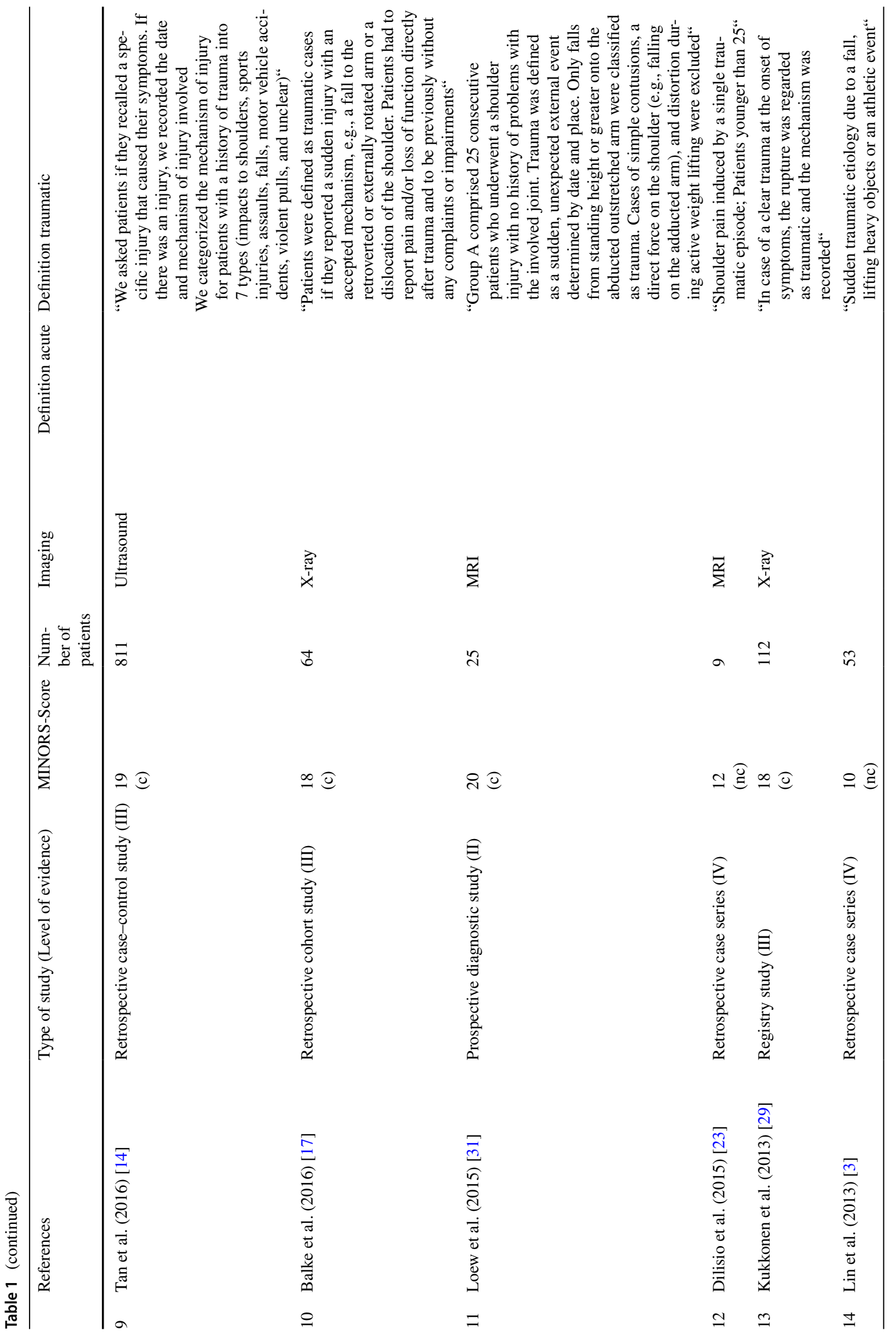




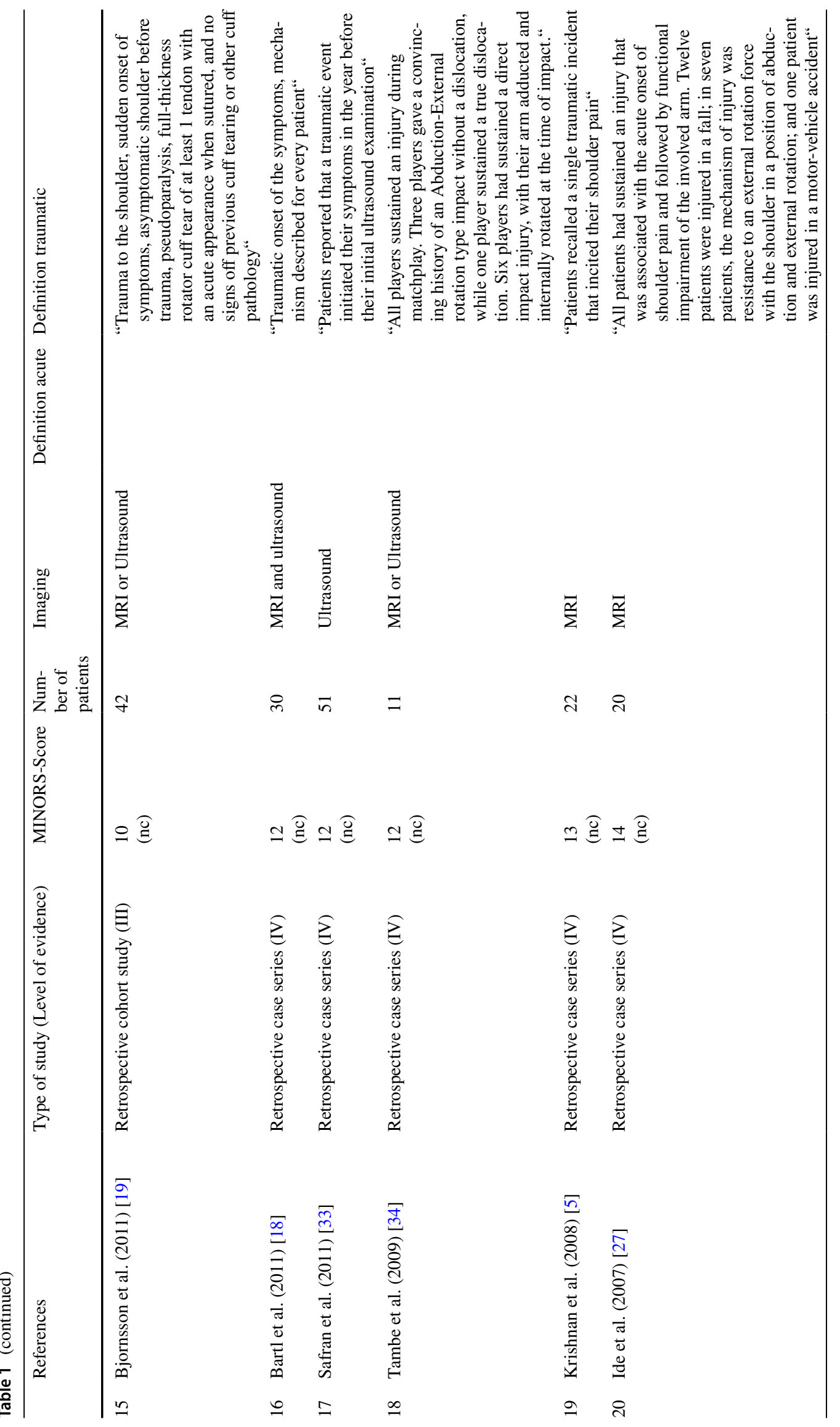




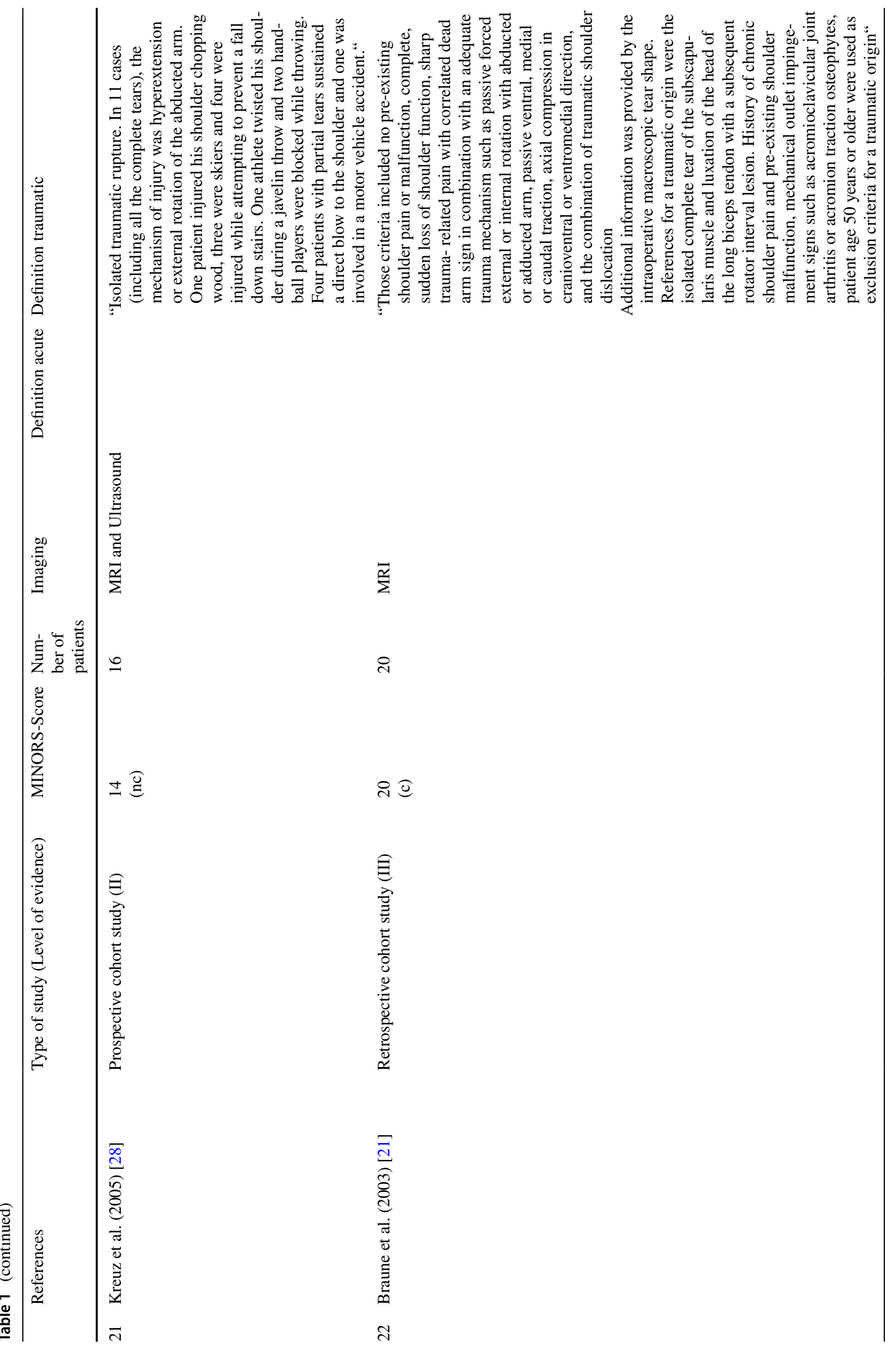




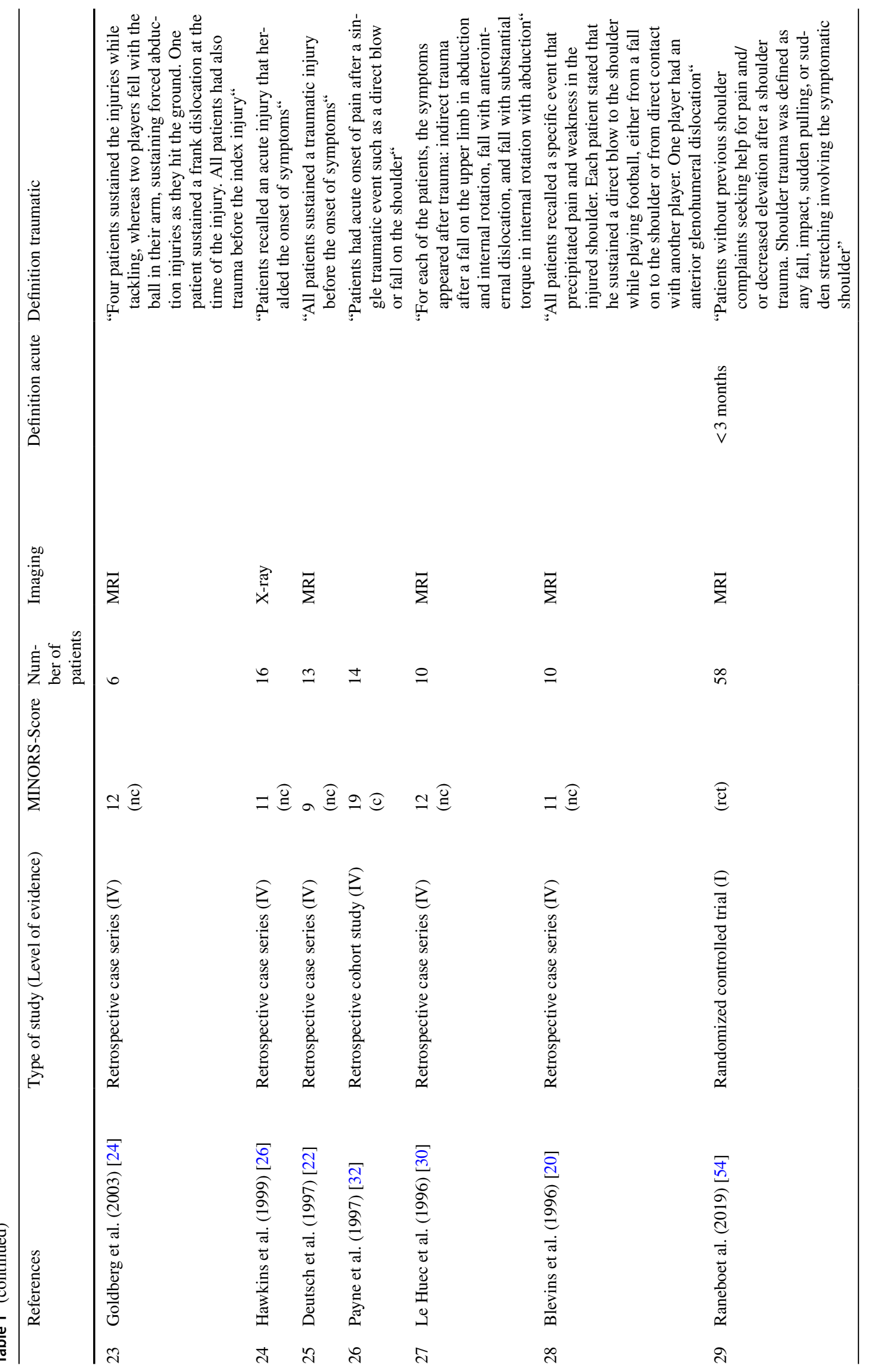




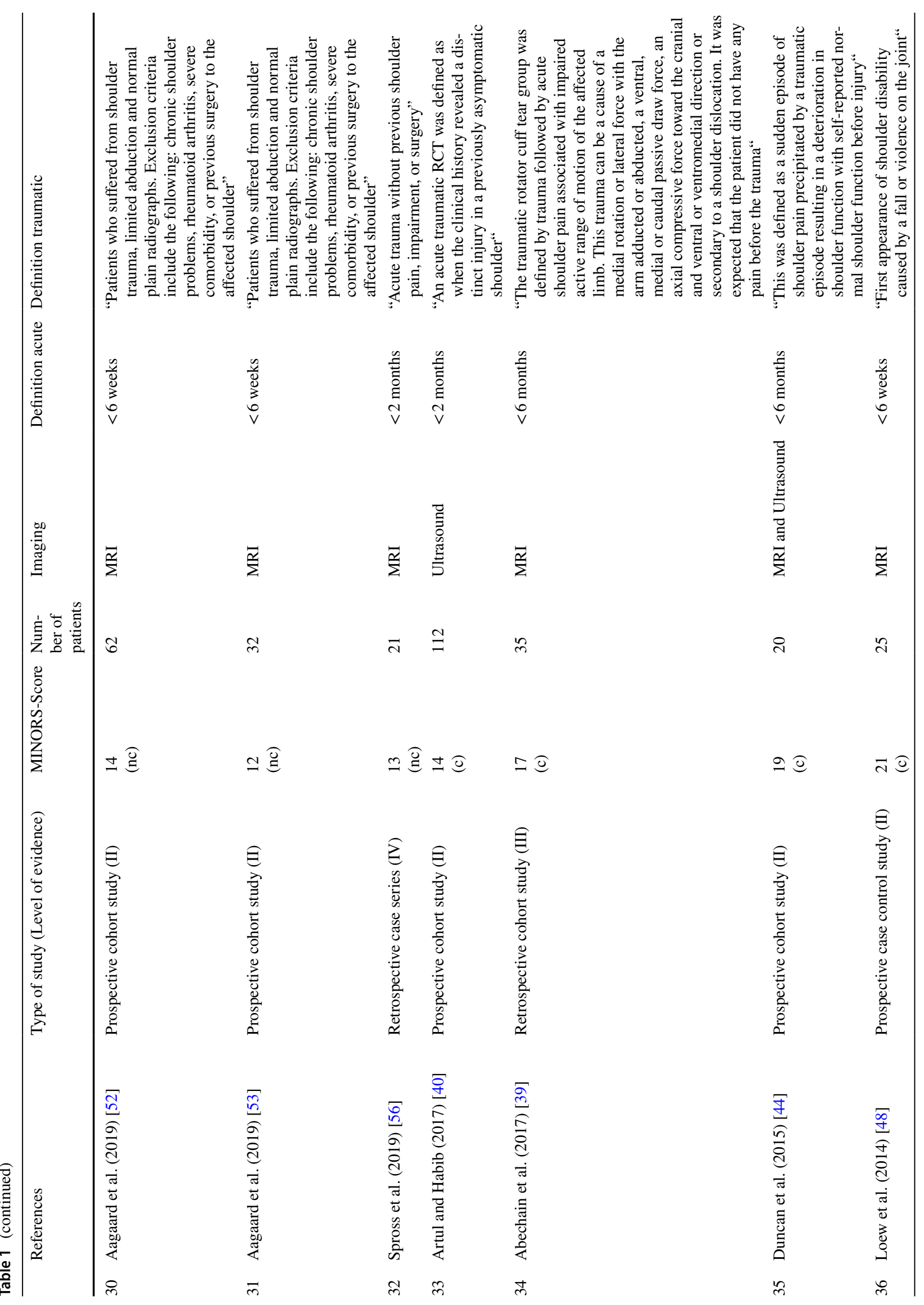




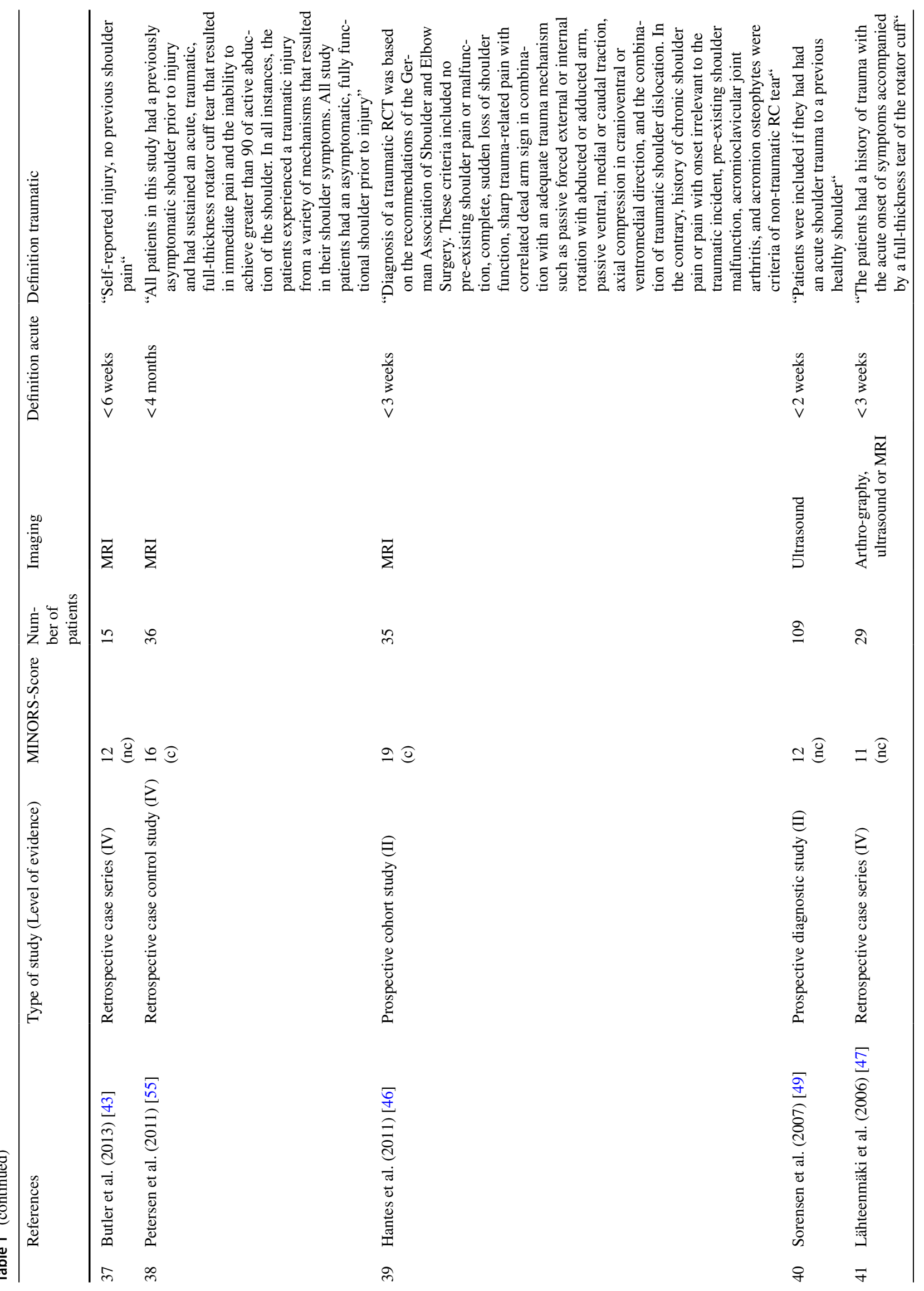




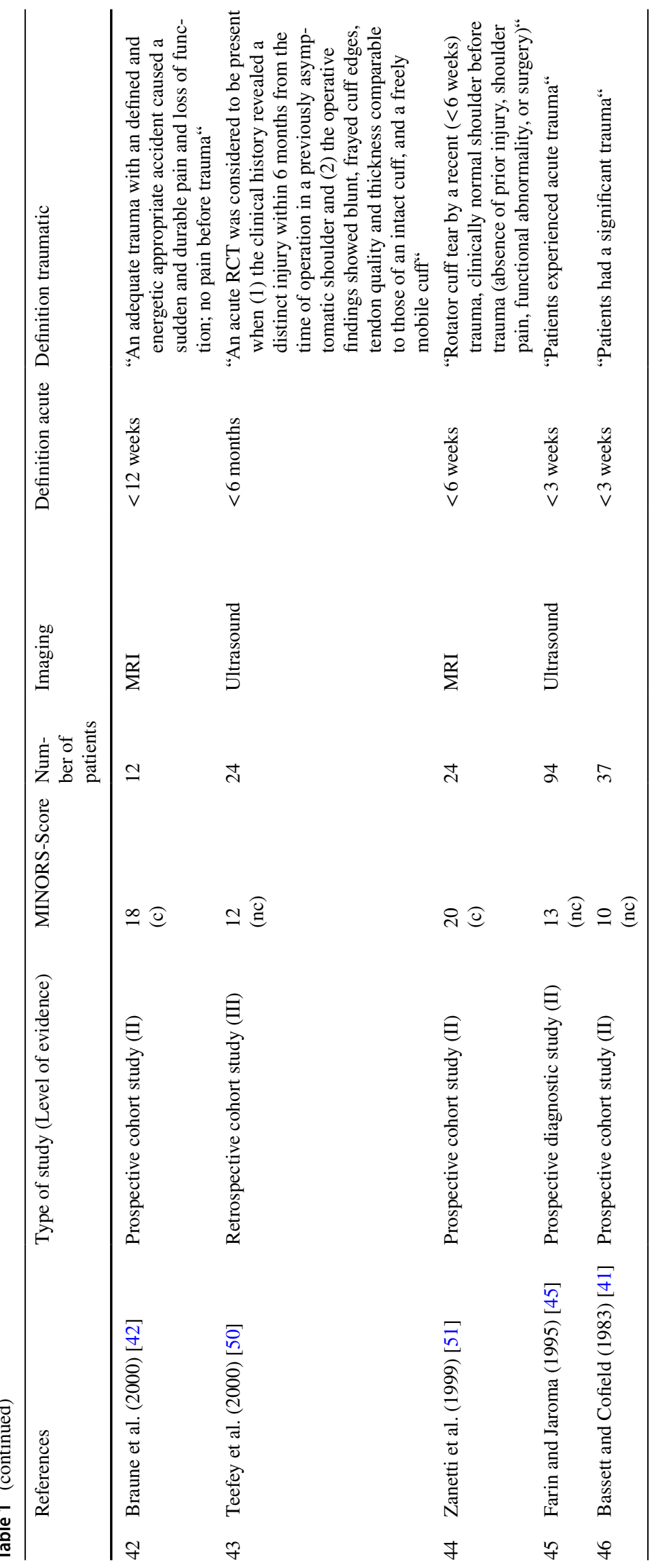


studies determining a time span from 2 to 6 months for their definition of "acute" [21, 39, 40, 44, 50, 54-56].

Ten studies contained specific explanations of their definition of the term "acute" [41, 43-47, 52, 53, 55, 56]. Studies performed by Basset and Cofield [41] and Farin and Jaroma [45] found lower degrees of retraction of the tendon and less scarring of the joint within the first 3 weeks after trauma and, therefore, proposed that surgical repair would be easier in this time frame. Therefore, the authors suggest, that 3 weeks should be considered as the time span for the definition of an acute RCT [41, 45]. Two studies further recommended surgery in a period of less than 3 weeks, referring to the study of Basset and Cofield [41, 46, 47]. Three articles set their definition of an acute RCT within 6-8 weeks after injury, using the average time span from several other clinical studies as a rationale for their definition $[43,53,56]$. Duncan et al. [44] argued that the evidence for defining acute and chronic remained unclear, using 6 months as a distinctive threshold. One study referred to the current Swedish national guideline that recommends surgery within 6 weeks [52]. Petersen et al. [55] reported favorable results for patients with RCTs treated within 4 months. The remaining eight studies provided no concise explanation for their definition of an acute RCT [39, 40, 42, 48-51, 54].

\section{Results for defining the term "traumatic"}

The term "traumatic" was defined in all 46 included studies $[3,5,13-56]$. The definitions of the term "traumatic" used in each publication are shown in Table 1.

For the definition of a traumatic lesion of the rotator cuff, all included studies required a sudden onset of symptoms following a patient-reported trauma to the shoulder $[3,5$, 13-56].

Furthermore, in 24 studies (52\%) only RCTs in previously asymptomatic patients were considered traumatic lesions [13, 15, 17, 19, 21, 25, 31, 35, 38-40, 42-44, 46, 48-56].

The trauma mechanism of the injury was detailed in 23 studies (50\%) [3, 13-18, 20, 21, 24, 27-32, 34, 38, 39, 46, $48,54,55]$. Of these, eleven publications $(24 \%)$ classified injuries with a specific and adequate injury mechanism as traumatic [3, 13, 16, 17, 21, 30, 31, 34, 39, 46, 54], whereas twelve studies $(26 \%)$ described the trauma mechanism without assessing the respective adequacy for the definition "traumatic" [14, 15, 18, 20, 24, 27-29, 32, 38, 48, 55]. More extended criteria were used in 14 publications (30\%) $[3,16,19,21,23,39,42,44,46,47,50,52,53,55]$. One study investigating traumatic tears only included patients younger than 25 years [23]. Loss of function was required in nine studies $[19,21,39,42,44,46,52,53,55]$. The intraoperative macroscopic or radiologic tear morphology was specified in five studies [3, 16, 21, 47, 50]. Furthermore, four publications defined RCTs as non-traumatic, if the patients had intraoperative or radiologic signs of previous shoulder dysfunction [19, 21, 46, 50].

\section{Discussion}

The main finding of this review is, that there exists no consensus on neither the term "acute" nor "traumatic" in the context of rotator cuff tears in the literature. In the studies reviewed for this article, RCT was defined as an acute injury with a time span of less than 2 weeks up to 6 months [39-56]. For defining a traumatic RCT, only $20 \%$ of the selected studies included both adequate injury patterns and appropriate radiological diagnostic modalities $[13,16,21$, $30,31,34,39,46,54]$.

\section{Definition of the term "acute"}

Similar to the biologic repair process of any other tendon tissue, the healing process of rotator cuff tears is time-dependent and commonly divided into three consecutive phases: (1) inflammation, (2) repair/proliferation and (3) remodeling [57-60]. Each of the phases depends on the interplay of different cell populations, cytokines and growth factors [61]. It is important to note, that the expression of growth factors and cytokines is highly time-dependent.

First of all, immediately after an injury, bleeding leads to the accumulation of cytokines and growth factors such as fibrin, fibronectin, interleukin1- $\beta$ (IL1- $\beta$ ), IL-6, tumor necrosis factor $\alpha$ (TNF- $\alpha)$, insulin-like growth factor-1 (IGF-1), platelet-derived growth factor (PDGF), basic fibroblast growth factor (bFGF) and transforming growth factor $\beta$ (TGF)- $\beta$. These growth factors peak in expression after 7 days $[62,63]$ and activate fibroblasts, which play a key role in the activation of the healing process, angiogenesis and remodeling of the delevoping extra-cellular matrix [61, 64, 65]. Furthermore, the release of these proteins results in the attraction of inflammatory cells such as neutrophils, macrophages and platelets, initiating the inflammatory phase, which lasts for approximately 7 days [57-59, 66].

This initial inflammatory phase is followed by a phase of repair and proliferation, lasting for approximately 2 weeks after the injury [57-60]. Herein, cell proliferation and angiogenesis are regulated by vasoactive and chemotactic factors such as VEGF and TGF- $\beta$, which activate collagen synthesis, angiogenesis and termination of cell proliferation. All of those factors peak 10 days after injury $[62,63]$. In this phase, fibroblasts begin to produce collagen, mainly type I and III $[57,58,62,63,67,68]$. While collagen type I is predominant in healthy tendons, the developing scar tissue contains a higher proportion of collagen type III [66].

The subsequent third phase of remodeling begins after a few weeks and can continue for several years $[36,66]$. 
As a part of the remodeling phase, IGF-1 release is predominant 3 weeks after injury and further stimulates the collagen synthesis [58]. As part of this process, a shift to a more physiologic distribution between collagen types I and III is occuring, resulting in an increasingly organized extra-cellular matrix [66, 67]. However, after a tear at the tendon-bone interface, the biological processes are not able to restore the native composition of the structure, resulting in a fibrovascular scar [69]. For example, several studies in animal models have shown that the regenerative tissue formed in supraspinatus tendons in rats is of inferior mechanical and histological quality compared to its native composition [60,67]. A decrease of all measured growth factors to control-group level was observed after 16 weeks, which could be considered as the biological equivalent to the completion of the healing process [63].

Radiologic imaging is helpful to detect RCTs and to distinguish between acute and chronic tears. Based on the literature, the MRI is considered the standard imaging technique to reliably diagnose an RCT [70-72]. As MRI is expensive, time-consuming and not ubiquitously available, ultrasound performed by experienced musculoskeletal clinicians is considered a valid imaging tool with reliable results for detecting RCT [73-75]. In case of an acute and traumatic rotator cuff tear, muscle edema and joint effusion and a wavelike appearance of the central part of the torn tendon, which is also known as the "kinking sign", can be detected [31]. In contrast, muscular atrophy and fatty infiltration are safe signs for a chronic component of the RCT, which can be visualized considerably more precise by MRI. However, the degree of tendon retraction and thinning of the tendon are unspecific signs and insufficient to distinguish between acute and chronic tears [31]. In the included studies, either ultrasound or MRI was used in 40 of 46 studies (87\%) [5, 13-16, 18-25, 27, 28, $30,31,33-40,42-56]$. In the remaining six studies (13\%), only X-ray imaging was used or no imaging modality was employed at all [3, 17, 26, 29, 32, 41].

Apart from radiologic imaging, histological investigations may provide information regarding the causality of the RCT. For example, thinning and disorientation of collagen fibers, vascular proliferation, calcification, myxoid degeneration and pronounced chondroid metaplasia can be considered as signs of pre-existing damage or degenerative changes of the rotator cuff tendons [76]. Acute injuries on the other hand, are characterized by hemosiderin appearence, hypervascularization and regenerative changes [77, 78]. While histopathological examinations may facilitate an ex post classification of the RCT type, it is not feasible to exclusively rely on histopathological examinations, when differentiating between acute and chronic RCTs - due to the heterogeneous and contradictory results and general impracticality in the clinical setting [42].

\section{Definition of the term "traumatic"}

Several factors, including history of trauma and mechanism of injury, contribute to the definition of a traumatic RCT. In terms of injury mechanisms, it is important to define truly traumatic tears more precisely and to distinguish them from RCTs resulting from inadequate injury mechanisms such as contusions, minor impacts or active muscle contractions during weight lifting $[79,80]$.

From a biomechanical point of view, various injury patterns can lead to excessive eccentric loading and overstretching of the tendons of the rotator cuff resulting in a traumatic RCT [80]. These mechanisms include shearing of the tendons on the glenoid rim, when the maximal tolerated rotation angle is exceeded. For example, a staircase fall with the attempt to prevent falling by holding on the railing results in a passively forced external or internal rotation and abduction with a massive overstretching of anterocranial or posterocranial structures, respectively, possibly leading to a RCT [79, 80]. In addition, axial compression and passive traction can lead to an RCT-a mechanism present in incidents such as a fall on the retroverted arm, a high velocity accident or unprepared catching of a heavy load. Similarly, a shoulder dislocation represents an adequate mechanism capable of causing injury to a healthy rotator cuff tendon $[21,31,39,46,80]$.

While all included studies reported shoulder trauma as the cause of injury [3, 5, 13-56], only 24 of the 46 studies (52\%) explicitly reported, that the injuries occurred in previously asymptomatic patients $[13,15,17,19,21,25,31,35$, $38-40,42-44,46,48-56]$. In addition, only eleven studies (24\%) described a specific injury mechanism, that could be considered adequate for a traumatic RCT [1, 4, 9, 16, 33, 48, $50,52,66,71,75]$.

\section{Call for standardization in nomenclature}

After reviewing the existing literature, we believe that the terms "acute" and "traumatic" must be considered in combination. The underlying rationale is to exclude so called "acute on chronic"-lesions, where an inadequate trauma leads to a rupture of a pre-damaged rotator cuff tendon [31]. Those tears may not have the same healing capacities as primarily traumatic RCTs. To categorise an RCT as "traumatic", the patient-reported trauma needs be adequate and follow a biomechanically plausible injury mechanism. There must be a clear differentiation from minor traumatic incidents or inadequate injury mechanisms, indicative of a nontraumatic tear of other etiology. Moreover, for an RCT to be considered traumatic, a previously asymptomatic patient needs to report a sudden onset of symptoms in the shoulder after the trauma. 
To be able to detect a truly traumatic and acute RCT, imaging should be performed within the first 2 weeks after injury, as the aforementioned radiologic properties of acute RCT such as muscle edema, joint effusion and the kinking sign can be visualised best in this time interval. In general, RCT should be visualised by ultrasound or MRI for an adequate statement about the ruptured tendon and possible concomitant pathologies. MRI is considered the gold standard imaging modality for RCT, as it allows further assessment of intraarticular structures and, more importantly, enables to detect signs of degenerative changes [70-72]. Histological investigations do not seem to be mandatory, as no clear evidence could be produced, that this modality is a reliable and practial tool to distinguish between acute and chronic rotator cuff tears.

Nonetheless, it must be taken into account, that due to the very complex interaction of growth factors, cytokines and involved cells, no comprehensive statement about the healing mechanisms and the ideal therapeutic time span for surgery in acute RCT can be made. Yet taking the decrease of most growth factors, cytokines and the collagen shift within the tear zone 8 weeks after trauma into account [58, 59, 63], it must be assumed that the healing capacity is significantly inferior after this period. Therefore, we recommend a time span of no more than 8 weeks to attempt a surgical repair of an acute RCT, to still benefit from superior biological healing capacities posttraumatically. A time period of more than 4 months after trauma appears to be generally unfavorable, due to the dynamics of the aforementioned physiological healing capacities [21, 39, 40, 44, 50, 54-56].

Our proposed definitions may help standardising the use of the terms "acute" and "traumatic" and, therefore, improve future understanding of the outcomes following rotator cuff repair, but further specification and elucidation of the exact healing processes is required. We are also aware of the inherent limitations implicated in our proposed definitions: First, a significant number of patients does not present within 2 weeks following trauma, making it difficult to detect signs of acute ruptures on ultrasound or MRI. Second, even if the patient presents in time, imaging modalities may not be available in time, especially in rural areas. Third, the exact trauma mechanism is scarcely comprehensible ex post, as the patient may not recall the exact details during the trauma. However, we believe, that it is of critical importance to attain guidelines for the definition of the terms acute and traumatic in the context of rotator cuff tears to be able to compare outcomes of future studies.

\section{Conclusion}

The term "acute" should be reserved for RCT showing muscle edema, wavelike appearance of the central part of the torn tendon, and joint effusion, which typically requires adequate imaging within 2 weeks from trauma. Repair of acute tears should occur within 8 weeks from trauma to benefit from possibly superior biological healing capacities. The term "traumatic" should be used for a sudden onset of symptoms in a previously asymptomatic patient, triggered by an adequate trauma, e.g., a fall on the retroverted arm with an axial cranioventral force or a traumatic shoulder dislocation.

Author contributions All authors contributed in a significant way in writing and editing the manuscript. ABI and JP conceived of the idea for the systematic review and made substantial contributions to conception, design and writing. HD, BE and MI performed the literature search. JP and MF were engaged in writing the manuscript, provided research support, and supervised the literature search. AT and MCR provided figures and made edits to the manuscript. All authors read and approved the final manuscript. All authors provided critical feedback and helped shape the analysis and manuscript. All authors read and approved the final manuscript.

Funding Open Access funding enabled and organized by Projekt DEAL.

Availability of data and material, code availability Not applicable.

\section{Compliance with ethical standards}

Conflict of interest Jonas Pogorzelski, Bernd Erber, Alexander Themessl, Marco-Christopher Rupp, Matthias Feucht, Andreas B. Imhoff, Hannes Degenhardt, and Markus Irger declare no conflict of interest.

Ethical approval Ethical approval statement not applicable.

Informed consent Informed consent statement not applicable.

Open Access This article is licensed under a Creative Commons Attribution 4.0 International License, which permits use, sharing, adaptation, distribution and reproduction in any medium or format, as long as you give appropriate credit to the original author(s) and the source, provide a link to the Creative Commons licence, and indicate if changes were made. The images or other third party material in this article are included in the article's Creative Commons licence, unless indicated otherwise in a credit line to the material. If material is not included in the article's Creative Commons licence and your intended use is not permitted by statutory regulation or exceeds the permitted use, you will need to obtain permission directly from the copyright holder. To view a copy of this licence, visit http://creativecommons.org/licenses/by/4.0/.

\section{References}

1. Oh LS, Wolf BR, Hall MP, Levy BA, Marx RG (2007) Indications for rotator cuff repair: a systematic review. Clin Orthop Relat Res 455:52-63. https://doi.org/10.1097/BLO.0b013e31802fc175

2. Azzam MG, Dugas JR, Andrews JR, Goldstein SR, Emblom BA, Cain EL Jr (2018) Rotator cuff repair in adolescent athletes. Am J Sports Med 46(5):1084-1090. https://doi.org/10.1177/03635 46517752919 
3. Lin EC, Mall NA, Dhawan A, Sherman SL, McGill KC, Provencher MT, Nicholson GP, Cole BJ, Solomon DJ, Verma NN, Romeo AA (2013) Arthroscopic primary rotator cuff repairs in patients aged younger than 45 years. Arthroscopy 29(5):811-817. https://doi.org/10.1016/j.arthro.2013.01.015

4. MacKechnie MA, Chahal J, Wasserstein D, Theodoropoulos JS, Henry P, Dwyer T (2014) Repair of full-thickness rotator cuff tears in patients aged younger than 55 years. Arthroscopy 30(10):1366-1371. https://doi.org/10.1016/j.arthro.2014.05.011

5. Krishnan SG, Harkins DC, Schiffern SC, Pennington SD, Burkhead WZ (2008) Arthroscopic repair of full-thickness tears of the rotator cuff in patients younger than 40 years. Arthroscopy 24(3):324-328. https://doi.org/10.1016/j.arthro.2007.09.005

6. Lazarides AL, Alentorn-Geli E, Choi JH, Stuart JJ, Lo IK, Garrigues GE, Taylor DC (2015) Rotator cuff tears in young patients: a different disease than rotator cuff tears in elderly patients. J Shoulder Elbow Surg 24(11):1834-1843. https://doi.org/10.1016/j. jse.2015.05.031

7. Dwyer T, Razmjou H, Holtby R (2015) Full-thickness rotator cuff tears in patients younger than 55 years: clinical outcome of arthroscopic repair in comparison with older patients. Knee Surg Sports Traumatol Arthrosc 23(2):508-513. https://doi.org/10.1007/s0016 7-014-3094-2

8. Hantes ME, Ono Y, Raoulis VA, Doxariotis N, Venouziou A, Zibis A, Vlychou M (2018) Arthroscopic single-row versus double-row suture bridge technique for rotator cuff tears in patients younger than 55 years: a prospective comparative study. Am J Sports Med 46(1):116-121. https://doi.org/10.1177/0363546517 728718

9. Moher D, Shamseer L, Clarke M, Ghersi D, Liberati A, Petticrew M, Shekelle P, Stewart LA (2015) Preferred reporting items for systematic review and meta-analysis protocols (PRISMA-P) 2015 statement. Syst Rev 4:1. https://doi.org/10.1186/2046-4053-4-1

10. Levels of Evidence Working Group O (2011) The Oxford 2011 Levels of Evidence. Oxford Centre for Evidence-Based Medicine

11. Wright JG, Swiontkowski MF, Heckman JD (2003) Introducing levels of evidence to the journal. J Bone Joint Surg Am 85(1):1-3

12. Slim K, Nini E, Forestier D, Kwiatkowski F, Panis Y, Chipponi J (2003) Methodological index for non-randomized studies (minors): development and validation of a new instrument. ANZ J Surg 73(9):712-716. https://doi.org/10.104 6/j.1445-2197.2003.02748.x

13. Aagaard KE, Hanninen J, Abu-Zidan FM, Lunsjo K (2018) Physical therapists as first-line diagnosticians for traumatic acute rotator cuff tears: a prospective study. Eur J Trauma Emerg Surg 44(5):735-745. https://doi.org/10.1007/s00068-017-0883-6

14. Tan M, Lam PH, Le BT, Murrell GA (2016) Trauma versus no trauma: an analysis of the effect of tear mechanism on tendon healing in 1300 consecutive patients after arthroscopic rotator cuff repair. J Shoulder Elbow Surg 25(1):12-21. https://doi. org/10.1016/j.jse.2015.06.023

15. Teratani $\mathrm{T}$ (2017) Comparison of the epidemiology and outcomes of traumatic and nontraumatic rotator cuff tears. J Orthop 14(1):166-170. https://doi.org/10.1016/j.jor.2016.12.007

16. Walcott ME, Daniels SD, Sinz NJ, Field LD, Higgins LD (2017) Traumatic full-thickness transtendinous rotator cuff tears: a case series. J Shoulder Elbow Surg 26(1):62-67. https://doi. org/10.1016/j.jse.2016.04.023

17. Balke M, Liem D, Greshake O, Hoeher J, Bouillon B, Banerjee M (2016) Differences in acromial morphology of shoulders in patients with degenerative and traumatic supraspinatus tendon tears. Knee Surg Sports Traumatol Arthrosc 24(7):2200-2205. https://doi.org/10.1007/s00167-014-3499-y

18. Bartl C, Scheibel M, Magosch P, Lichtenberg S, Habermeyer P (2011) Open repair of isolated traumatic subscapularis tendon tears. Am J Sports Med 39(3):490-496. https://doi. org/10.1177/0363546510388166

19. Bjornsson HC, Norlin R, Johansson K, Adolfsson LE (2011) The influence of age, delay of repair, and tendon involvement in acute rotator cuff tears: structural and clinical outcomes after repair of 42 shoulders. Acta Orthop 82(2):187-192. https://doi. org/10.3109/17453674.2011.566144

20. Blevins FT, Hayes WM, Warren RF (1996) Rotator cuff injury in contact athletes. Am J Sports Med 24(3):263-267. https://doi. org/10.1177/036354659602400303

21. Braune C, von Eisenhart-Rothe R, Welsch F, Teufel M, Jaeger A (2003) Mid-term results and quantitative comparison of postoperative shoulder function in traumatic and non-traumatic rotator cuff tears. Arch Orthop Trauma Surg 123(8):419-424. https://doi. org/10.1007/s00402-003-0548-2

22. Deutsch A, Altchek DW, Veltri DM, Potter HG, Warren RF (1997) Traumatic tears of the subscapularis tendon. Clinical diagnosis, magnetic resonance imaging findings, and operative treatment. Am J Sports Med 25 (1):13-22. https://doi.org/10.1177/03635 4659702500104

23. Dilisio MF, Noel CR, Noble JS, Bell RH (2015) Traumatic supraspinatus tears in patients younger than 25 years. Orthopedics 38(7):e631-634. https://doi.org/10.3928/01477447-20150701-63

24. Goldberg JA, Chan KY, Best JP, Bruce WJ, Walsh W, Parry W (2003) Surgical management of large rotator cuff tears combined with instability in elite rugby football players. Br J Sports Med 37 (2):179-181; discussion 181. https://doi.org/10.1136/ bjsm.37.2.179

25. Haviv B, Rutenberg TF, Bronak S, Yassin M (2018) Arthroscopic rotator cuff surgery following shoulder trauma improves outcome despite additional pathologies and slow recovery. Knee Surg Sports Traumatol Arthrosc 26(12):3804-3809. https://doi. org/10.1007/s00167-018-4969-4

26. Hawkins RJ, Morin WD, Bonutti PM (1999) Surgical treatment of full-thickness rotator cuff tears in patients 40 years of age or younger. J Shoulder Elbow Surg 8(3):259-265. https://doi. org/10.1016/s1058-2746(99)90139-8

27. Ide J, Tokiyoshi A, Hirose J, Mizuta H (2007) Arthroscopic repair of traumatic combined rotator cuff tears involving the subscapularis tendon. J Bone Joint Surg Am 89(11):2378-2388. https://doi. org/10.2106/jbjs.G.00082

28. Kreuz PC, Remiger A, Lahm A, Herget G, Gachter A (2005) Comparison of total and partial traumatic tears of the subscapularis tendon. J Bone Joint Surg Br 87(3):348-351. https://doi. org/10.1302/0301-620x.87b3.15515

29. Kukkonen J, Joukainen A, Itala A, Aarimaa V (2013) Operatively treated traumatic versus non-traumatic rotator cuff ruptures: a registry study. Ups J Med Sci 118(1):29-34. https://doi. org/10.3109/03009734.2012.715597

30. Le Huec JC, Schaeverbeke T, Moinard M, Kind M, Diard F, Dehais J, Le Rebeller A (1996) Traumatic tear of the rotator interval. J Shoulder Elbow Surg 5(1):41-46. https://doi.org/10.1016/ s1058-2746(96)80029-2

31. Loew M, Magosch P, Lichtenberg S, Habermeyer P, Porschke F (2015) How to discriminate between acute traumatic and chronic degenerative rotator cuff lesions: an analysis of specific criteria on radiography and magnetic resonance imaging. J Shoulder Elbow Surg 24(11):1685-1693. https://doi.org/10.1016/j.jse.2015.06.005

32. Payne LZ, Altchek DW, Craig EV, Warren RF (1997) Arthroscopic treatment of partial rotator cuff tears in young athletes. A preliminary report. Am J Sports Med 25 (3):299-305. https://doi. org/10.1177/036354659702500305

33. Safran O, Schroeder J, Bloom R, Weil Y, Milgrom C (2011) Natural history of nonoperatively treated symptomatic rotator 
cuff tears in patients 60 years old or younger. Am J Sports Med 39(4):710-714. https://doi.org/10.1177/0363546510393944

34. Tambe A, Badge R, Funk L (2009) Arthroscopic rotator cuff repair in elite rugby players. Int J Shoulder Surg 3(1):8-12. https://doi. org/10.4103/0973-6042.50876

35. Haviv B, Rutenberg TF, Yaari L, Khatib M, Rath E, Yassin M (2019) Which patients are less likely to improve after arthroscopic rotator cuff repair? Acta Orthop Traumatol Turc 53(5):356-359. https://doi.org/10.1016/j.aott.2019.02.003

36. Bashir A, Seth S, Wani IH, Farooq M, Ul Gani N, Naqshi BF (2018) Mini-open rotator cuff tear repair: an institutional experience with a midterm follow-up. Ortop Traumatol Rehabil 20(5):383-387. https://doi.org/10.5604/01.3001.0012.8274

37. Hasler A, Boyce G, Schallberger A, Jost B, Catanzaro S, Gerber C (2019) Arthroscopic repair of isolated subscapularis tears: clinical outcome and structural integrity with a minimum follow-up of 4.6 years. J Shoulder Elbow Surg 28 (11):2171-2180. https://doi. org/10.1016/j.jse.2019.03.024

38. Plachel F, Korn G, Ortmaier R, Hoffelner T, Resch H, Moroder P (2019) Repair failure increases the risk of developing secondary glenohumeral osteoarthritis: a long-term follow-up after open repair of large subscapularis tendon tears. Orthop Traumatol Surg Res 105(8):1529-1533. https://doi.org/10.1016/j.otsr.2019.09.021

39. Abechain JJK, Godinho GG, Matsunaga FT, Netto NA, Daou JP, Tamaoki MJS (2017) Functional outcomes of traumatic and non-traumatic rotator cuff tears after arthroscopic repair. World J Orthop 8(8):631-637. https://doi.org/10.5312/wjo.v8.i8.631

40. Artul S, Habib G (2017) Ultrasonographic clues for acuity/chronicity of rotator cuff tear. Eur J Rheumatol 4(4):260-263. https:// doi.org/10.5152/eurjrheum.2017.17047

41. Bassett RW, Cofield RH (1983) Acute tears of the rotator cuff. The timing of surgical repair. Clin Orthop Relat Res 175:18-24

42. Braune C, Gramlich H, Habermeyer P (2000) The macroscopic aspect of rotator cuff tears in traumatic and nontraumatic rupture cases. Unfallchirurg 103(6):462-467. https://doi.org/10.1007/ s001130050566

43. Butler BR, Byrne AN, Higgins LD, Shah A, Fowler RL (2013) Results of the repair of acute rotator cuff tears is not influenced by tear retraction. Int J Shoulder Surg 7(3):91-99. https://doi. org/10.4103/0973-6042.118906

44. Duncan NS, Booker SJ, Gooding BW, Geoghegan J, Wallace WA, Manning PA (2015) Surgery within 6 months of an acute rotator cuff tear significantly improves outcome. J Shoulder Elbow Surg 24(12):1876-1880. https://doi.org/10.1016/j.jse.2015.05.043

45. Farin PU, Jaroma H (1995) Acute traumatic tears of the rotator cuff: value of sonography. Radiology 197(1):269-273. https://doi. org/10.1148/radiology.197.1.7568835

46. Hantes ME, Karidakis GK, Vlychou M, Varitimidis S, Dailiana Z, Malizos KN (2011) A comparison of early versus delayed repair of traumatic rotator cuff tears. Knee Surg Sports Traumatol Arthrosc 19(10):1766-1770. https://doi.org/10.1007/s0016 7-011-1396-1

47. Lahteenmaki HE, Virolainen P, Hiltunen A, Heikkila J, Nelimarkka OI (2006) Results of early operative treatment of rotator cuff tears with acute symptoms. J Shoulder Elbow Surg 15(2):148153. https://doi.org/10.1016/j.jse.2005.07.006

48. Loew M, Porschke FB, Riedmann S, Magosch P, Lichtenberg S (2014) Zur Unterscheidung zwischen traumatischer und degenerativer Rotatorenmanschettenruptur - eine klinische und radiologische Untersuchung. Obere Extremität 9(3):209-214. https ://doi.org/10.1007/s11678-014-0271-3

49. Sorensen AK, Bak K, Krarup AL, Thune CH, Nygaard M, Jorgensen U, Sloth C, Torp-Pedersen S (2007) Acute rotator cuff tear: do we miss the early diagnosis? A prospective study showing a high incidence of rotator cuff tears after shoulder trauma. J
Shoulder Elbow Surg 16(2):174-180. https://doi.org/10.1016/j. jse.2006.06.010

50. Teefey SA, Middleton WD, Bauer GS, Hildebolt CF, Yamaguchi K (2000) Sonographic differences in the appearance of acute and chronic full-thickness rotator cuff tears. J Ultrasound Med 19 (6):377-378; quiz 383. https://doi.org/10.7863/jum.2000.19.6.377

51. Zanetti M, Weishaupt D, Jost B, Gerber C, Hodler J (1999) MR imaging for traumatic tears of the rotator cuff: high prevalence of greater tuberosity fractures and subscapularis tendon tears. AJR Am J Roentgenol 172(2):463-467. https://doi.org/10.2214/ ajr.172.2.9930804

52. Aagaard KE, Lunsjo K, Frobell R (2019) Early repair of traumarelated full-thickness rotator cuff tears does not eliminate the problem of healing failure. Bone Joint J 101-b (5):603-609. https ://doi.org/10.1302/0301-620x.101b5.Bjj-2018-0867.R1

53. Aagaard KE, Randeblad P, Abu-Zidan FM, Lunsjo K (2019) Return to work after early repair of acute traumatic rotator cuff tears. Eur J Trauma Emerg Surg. https://doi.org/10.1007/s0006 8-019-01074-9

54. Ranebo MC, Bjornsson Hallgren HC, Holmgren T, Adolfsson LE (2020) Surgery and physiotherapy were both successful in the treatment of small, acute, traumatic rotator cuff tears: a prospective randomized trial. J Shoulder Elbow Surg 29(3):459470. https://doi.org/10.1016/j.jse.2019.10.013

55. Petersen SA, Murphy TP (2011) The timing of rotator cuff repair for the restoration of function. J Shoulder Elbow Surg 20(1):62-68. https://doi.org/10.1016/j.jse.2010.04.045

56. Spross C, Behrens G, Dietrich TJ, Olaf Kim CH, Puskas GJ, Zdravkovic V, Jost B (2019) Early arthroscopic repair of acute traumatic massive rotator cuff tears leads to reliable reversal of pseudoparesis: clinical and radiographic outcome. Arthroscopy 35(2):343-350. https://doi.org/10.1016/j.arthro.2018.08.048

57. Zumstein MA, Ladermann A, Raniga S, Schar MO (2017) The biology of rotator cuff healing. Orthop Traumatol Surg Res 103(1s):S1-s10. https://doi.org/10.1016/j.otsr.2016.11.003

58. Molloy T, Wang Y, Murrell GAC (2003) The roles of growth factors in tendon and ligament healing. Sports Med 33(5):381-394

59. Gulotta LV, Rodeo SA (2009) Growth factors for rotator cuff repair. Clin Sports Med 28(1):13-23. https://doi.org/10.1016/j. csm.2008.09.002

60. Carpenter T, Flanagan DeBano, Soslowsky (1998) Rotator cuff defect healing: a biomechanicai and histologic analysis in an animal model. J Shoulder Elbow Surg 7(6):599-605

61. Nichols AEC, Best KT, Loiselle AE (2019) The cellular basis of fibrotic tendon healing: challenges and opportunities. Transl Res 209:156-168. https://doi.org/10.1016/j.trs1.2019.02.002

62. Kobayashi M, Itoi E, Minagawa H, Miyakoshi N, Takahashi S, Tuoheti Y, Okada K, Shimada Y (2006) Expression of growth factors in the early phase of supraspinatus tendon healing in rabbits. J Shoulder Elbow Surg 15(3):371-377. https://doi.org/10.1016/j. jse.2005.09.003

63. Wurgler-Hauri CC, Dourte LM, Baradet TC, Williams GR, Soslowsky LJ (2007) Temporal expression of 8 growth factors in tendon-to-bone healing in a rat supraspinatus model. J Shoulder Elbow Surg 16(5 Suppl):S198-203. https://doi.org/10.1016/j. jse.2007.04.003

64. des Jardins-Park HE, Foster DS, Longaker MT (2018) Fibroblasts and wound healing: an update. Regen Med 13 (5):491-495. https ://doi.org/10.2217/rme-2018-0073

65. Bainbridge $P$ (2013) Wound healing and the role of fibroblasts. J Wound Care 22 (8):407-408, 410-412. https://doi.org/10.12968/ jowc.2013.22.8.407

66. Edwards S, Lynch S, Saltzman M, Terry M, Nuber G (2011) Biologic and pharmacologic augmentation of rotator cuff repairs. J Am Acad Orthop Surg 19(10):583-589 
67. Galatz LM, Sandell LJ, Rothermich SY, Das R, Mastny A, Havlioglu N, Silva MJ, Thomopoulos S (2006) Characteristics of the rat supraspinatus tendon during tendon-to-bone healing after acute injury. J Orthop Res 24(3):541-550. https://doi.org/10.1002/ jor.20067

68. Morita W, Dakin SG, Snelling SJB, Carr AJ (2017) Cytokines in tendon disease. Bone Joint Res 6:656-664. https://doi. org/10.1302/20463758.612

69. Angeline ME, Rodeo SA (2012) Biologics in the management of rotator cuff surgery. Clin Sports Med 31(4):645-663. https://doi. org/10.1016/j.csm.2012.07.003

70. Sharma G, Bhandary S, Khandige G, Kabra U (2017) MR imaging of rotator cuff tears: correlation with arthroscopy. J Clin Diag Res JCDR 11 (5):TC24-TC27. https://doi.org/10.7860/ JCDR/2017/27714.9911

71. Fischer CA, Weber M-A, Neubecker C, Bruckner T, Tanner M, Zeifang F (2015) Ultrasound vs. MRI in the assessment of rotator cuff structure prior to shoulder arthroplasty. J Orthop 12 (1):2330. https://doi.org/10.1016/j.jor.2015.01.003

72. Lenza M, Buchbinder R, Takwoingi Y, Johnston RV, Hanchard NC, Faloppa F (2013) Magnetic resonance imaging, magnetic resonance arthrography and ultrasonography for assessing rotator cuff tears in people with shoulder pain for whom surgery is being considered. Coch Datab Syst Rev. https://doi.org/10.1002/14651 858.CD009020.pub2

73. J C M Rutten M, Spaargaren G-J, van Loon T, C. de Waal Malefijt M, A L M Kiemeney L, Jager G (2009) Detection of rotator cuff tears: the value of MRI following ultrasound. https://doi. org/10.1007/s00330-009-1561-9
74. Zanetti M, Hodler J (2000) Imaging of degenerative and posttraumatic disease in the shoulder joint with ultrasound. Eur J Radiol 35(2):119-125. https://doi.org/10.1016/s0720-048x(00)00227-8

75. de Jesus JO, Parker L, Frangos AJ, Nazarian LN (2009) Accuracy of MRI, MR arthrography, and ultrasound in the diagnosis of rotator cuff tears: a meta-analysis. AJR Am J Roentgenol 192(6):1701-1707. https://doi.org/10.2214/ajr.08.1241

76. Hashimoto T, Nobuhara K, Hamada T (2003) Pathologic evidence of degeneration as a primary cause of rotator cuff tear. Clin Orthop Relat Res 415:111-120. https://doi.org/10.1097/01. blo.0000092974.12414.22

77. Moller HD, Evans CH, Maffulli N (2000) Current aspects of tendon healing. Orthopade 29(3):182-187

78. Movin T, Gad A, Reinholt FP, Rolf C (1997) Tendon pathology in long-standing achillodynia. Biopsy findings in 40 patients. Acta Orthop Scand 68 (2):170-175

79. Ludolph EJTuB (2008) Begutachtung der Zusammenhangstrennung der Rotatorenmanschette. 10 (3):316-318. https://doi. org/10.1007/s10039-007-1311-7

80. Loew M, Habermeyer P, Wiedemann E, Rickert M, Gohlke F (2000) Recommendations for diagnosis and expert assessment of traumatic rotator cuff lesions. Unfallchirurg 103(5):417-426. https ://doi.org/10.1007/s001130050560

Publisher's Note Springer Nature remains neutral with regard to jurisdictional claims in published maps and institutional affiliations. 